\title{
La imagen turística argentina en contexto internacional: política exterior de imagen nacional
}

\author{
Diego Navarro* \\ Consejo Nacional de Investigaciones Científicas y Técnicas \\ Universidad del Salvador
}

\section{Resumen}

Este escrito describe y explica la imagen turística argentina, categoría comprendida como un tipo de política exterior de imagen nacional. Se hizo un análisis cualitativo de las tres publicaciones promocionales de Argentina, diseñadas por el Ministerio de Turismo hacia el año 2000 y distribuidas en el exterior hasta la actualidad. Las variables y descripciones resultantes, organizadas alrededor de los tres elementos constitutivos de todo Estado, dibujaron una Argentina particular en términos de territorio, sociedad e instituciones. Los mensajes turísticos aparecen fuertemente enmarcados en el episteme eurocéntrico de la modernidad occidental: un paradigma extendido en el mundo durante los últimos cinco siglos, en tanto estrategia de dominación política y cultural, y que hoy se reinventa bajo el nombre de globalización.

\section{Palabras clave}

Argentina, imagen turística argentina, globalización modernidad.

Recibido: 16/11/2012 · Aceptado: 21/12/2012 


\title{
Argentinian Tourist Image in the International Context: National Image Foreign Policy
}

\author{
Diego Navarro \\ Consejo Nacional de Investigaciones Científicas y Técnicas \\ Universidad del Salvador
}

\begin{abstract}
This paper describes and explains the Argentinian tourist image as a foreign policy. For this purpose, the three main promotional brochures of Argentina as a tourist destination were qualitatively analyzed. They were designed by the Ministry of Tourism in 2000 and are actually distributed abroad. The resulting variables and descriptions, considering the three constitutive elements of any State, draw a picture of a peculiar Argentina in terms of territory, society and institutions. Tourist messages were firmly framed in the Eurocentric concept of western modernity: a paradigm spread worldwide for the last five centuries, as a political and cultural strategy of domination -nowadays revisited by the name of globalization.
\end{abstract}

\section{Key WORDS}

Argentina, Argentinian tourist image, globalization, modernity. 


\section{Introducción}

El estudio de la política exterior de imagen nacional depara la exploración, descripción y comprensión de un fenómeno que propone, al menos, tres niveles de intensidad, y cuya manifestación muchas veces coincide con momentos históricos sucesivos. En primer lugar, se observa que, desde que existen (más aún: para existir), los Estados se dan a conocer entre sus pares y comunican espontáneamente una imagen nacional; es posible denominar al conjunto de estas decisiones germinales protopolítica exterior de imagen nacional. En segundo lugar, se considera que en virtud de los objetivos de determinadas áreas de gestión del gobierno, los Estados formulan y distribuyen una determinada y deliberadamente fragmentaria imagen nacional; es decir, una política exterior sectorial de imagen nacional. En tercer lugar, por lo general preocupados por mejorar su posicionamiento internacional, en la última década numerosos Estados han diseñado y proyectado de manera intencional una imagen nacional integral o política de marca país, como es referida con creciente consenso.

Toda actuación estatal de promoción turística internacional constituye una acción del segundo tipo. En efecto, se trata de una política, en cuanto supone una intervención gubernamental que ha sido diseñada e implementada ex profeso. Es exterior, ya que está dirigida a públicos foráneos (aunque en el caso argentino, desde que es administrada por el Ministerio de Turismo, también es turística). La imagen nacional es su objeto, puesto que, consagrada a la persuasión de visitantes (preferentemente foráneos), recurre a la comunicación de los aspectos atractivos (y a la vez constitutivos) del Estado: elementos naturales y culturales, territorio y nación.

Preocupados por la política exterior y turística de imagen nacional de la Argentina, se focaliza aquí la descripción y comprensión de su objeto central: la imagen turística argentina (ITA). El punto de partida es la concepción de la imagen turística nacional como el conjunto de mensajes aparentemente fieles sobre una nación y su territorio (constituidos en destino turístico), emitidos por su gobierno y dirigidos a potenciales turistas extranacionales. Se trata de una conceptualización que resulta de un análisis que desarrollamos en otra ocasión (Navarro, 2010: 33-42).

La ITA fue observada en tres publicaciones promocionales diseñadas hacia el año 2000 por la antigua Secretaría de Turismo de la Nación (Ministerio de 
Turismo desde 2010) y distribuidas en el exterior por esta y la Cancillería en ferias especializadas o en las representaciones del servicio exterior. Se trata de los denominados folleto principal, mapa turístico y revista turística: el paquete promocional de la Argentina más distribuido entre el público foráneo durante la primera década del siglo corriente. Tal direccionamiento exterior es evidente en los idiomas de los impresos: español, inglés, francés, alemán, italiano y portugués; ocasionalmente, también árabe, chino, japonés y ruso. Cabe indicar que estas constituyen las únicas publicaciones integrales sobre la Argentina como destino turístico: otras observan una organización por regiones o por macroproductos turísticos. También conviene apuntar la preferencia por unidades de análisis impresas, más persistentes que las audiovisuales, virtuales y orales.

\section{Metodología}

Por una parte, se estudió el denominado folleto principal, que constituye un desplegable de tamaño estándar, introductorio de la Argentina como destino turístico. En su portada, una imagen de cardos contra el cielo simboliza con claridad a la bandera argentina. Por otra parte, se analizó el mapa turístico: impreso que goza de dilatadas dimensiones y ostensible utilidad para el turista, y que incluye una carta turístico-geográfica complementada con textos explicativos de numerosos atractivos turísticos. Por último, se revisó la revista turística: publicación que supera el medio centenar de páginas y que cuenta con una calidad de impresión superior.

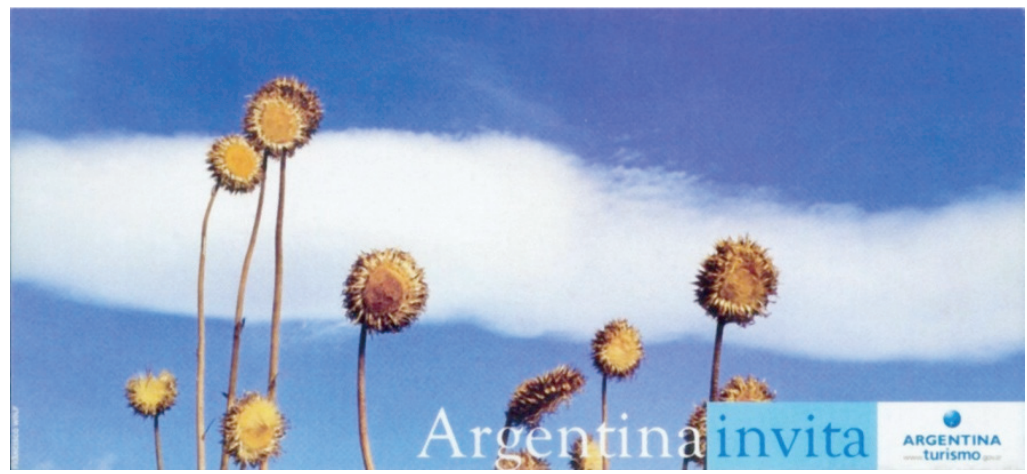

Portada del folleto principal (tapa) 
A simple vista el material revisado no deparaba más que diferencias físicas (forma, tamaño y extensión) y repetición de cuerpos discursivos: mapas turísticos (excepto en la revista), presentación de los bienes argentinos declarados patrimonio de la humanidad como atractivos centrales, un espacio destinado a "información de interés" y la organización de la oferta turística por macroproductos y regiones. Pero detrás de paisajes vistosos y situaciones agradables, mapas útiles y textos coloridos, sobrevienen determinados datos objetivos, exagerados y omitidos.

Las descripciones realizadas observaron una estrategia cualitativa en virtud de inquietudes sobre la construcción social de significados (Sautu, 1997: 236). Partimos de unas pocas variables elementales emergentes de nuestra categoría conceptual de imagen turística nacional: la preocupación por los mensajes identitarios e inventados, el interés por los contenidos sobre el territorio y la nación.

En principio, decidimos lecturas por unidad de estudio (folleto principal, mapa turístico y revista turística) por dos motivos: para cuidar el orden en el análisis de los datos y para no perder diferencias semánticas posibles entre una unidad y otra. Cada unidad fue estudiada en su totalidad.

En una segunda etapa, procedimos a la observación por código (fotográfico, gráfico y textual) en cada una de las unidades de análisis a fin de evitar las contaminaciones que implica la lectura simultánea de un mismo tema desde varios lenguajes. Esta aproximación impuso nuevas variables (o ajustes a las anteriores) en virtud de las características de cada lenguaje (por ejemplo: adjudicación del gentilicio "argentino" en los textos, presencia de personas en las fotos, etc.). Aquello de que en la investigación social la teoría es constantemente "reinterpretada y reconstruida a partir de la evidencia empírica” (Sautu, 1997: 229) fue propio de ese momento.

Luego, avanzamos en la descripción por temas ("productos turísticos”, "regiones turísticas”, “datos de interés”, entre otros) a fin de captar particularidades más veladas que, en algunos casos, condujeron a significaciones de relieve. A partir de los contenidos rescatados redefinimos las variables una vez más e incorporamos otras: diferenciación de presencias humanas en residentes o turistas, por citar algunas.

En un cuarto momento, reescribimos las descripciones procurando fundir los subtemas (región Norte, región Litoral, región Centro, etc., consideradas 
bajo el conjunto de regiones turísticas). Después de todo, la imagen turística argentina escapa al foco en cada región o producto. En línea con Otero (1997: 198), esta lectura agregada (actitud cuantitativa) desnudó nuevas observaciones, variables y ajustes (por ejemplo: comparación entre regiones respecto de dataciones), sin perjuicio de los matices ya detectados (actitud cualitativa).

Por último, reorganizamos la observación en torno de aquella cuarta generación de variables, ahora más maduras. Esta producción supuso una transformación de los contenidos empíricos en variables propias: tomamos distancia de la organización de contenidos dada por la Secretaría de Turismo y formulamos una estructura funcional a los objetivos de esta investigación. Durante este proceso, fue posible pulir nuevamente las variables y arribar a un conjunto final o quinta versión que presentamos agrupadas en "Resultados".

Los contenidos de los rasgos identitarios advertidos en las publicaciones de la Secretaría de Turismo fueron revisados a la luz de su adscripción disciplinar (geográfico, histórico), comparados con otros corpus paralelos o relacionados (literatura, educación), contextualizados en sus marcos políticos (por ejemplo el nacionalismo de los años treinta) y culturales (la matriz occidental, entre otros) y vinculados con sus antecedentes (ITA de 1950).

Se trató, en suma, de un proceso poco lineal, con avances y retrocesos permanentes, más bien en espiral. La estructura de variables finales, antes que un mandato inicial, resultó un punto de llegada. Productos confirmados, al igual que las descripciones puntuales, en una suerte de saturación empírica experimentada: la repetición de las mismas ideas en uno y otro código lingüístico y en uno y otro folleto refuerzan las diversas apreciaciones y avalan la validez interna del trabajo.

\section{Resulltados}

Casi una decena de variables fueron ganando cuerpo durante la observación de la ITA y, a la vez, describiendo una serie de contenidos recortados o silenciados, más otros ideados con fines específicos. Se trata de un conjunto de variables que reflejan un territorio (geoposicionamiento, configuración y extensión, composición natural), una sociedad (distribución, selección, intercambios) y determinadas instituciones (Estado y su organización, otras entidades). 
1. Geoposicionamiento. La ITA parte de un marco de inserción y proyección mundial, coherente con la apertura en construcción desde los años noventa. El recorte más decisivo consiste en la vinculación político-cultural con Europa Occidental y el Occidente moderno. Esta elección tiene correlato en la aceptación del contexto físico sudamericano por sobre la matriz político-cultural de Latinoamérica (en el folleto y el mapa, "La República Argentina situada en Sudamérica”). Asimismo, la conexión antártica tiene perfiles de proyección soberana (también en el folleto y el mapa, el triángulo antártico entre los meridianos 25 y $74^{\circ}$ Oeste es nominado como "Antártida Argentina”). Por otra parte, la Argentina turística simplifica su diversidad climática y se declara templada, a la vez que evita relacionarse con el trópico y el imaginario de pobreza y desidia con el que este es asociado (en la revista, el mapa de la República Argentina no incluye el trópico de Capricornio).

2. Soberanía territorial. La ITA confirma la nacionalidad de territorios cuyo dominio es indudable (en la revista, "la Mesopotamia argentina"; en el folleto y el mapa, "Is. Martín García (arg.)”, aclaración inexistente para otras islas). Se trata de una forma del mito nacional que, en cuanto pone en el suelo el origen de la argentinidad, ve en el territorio un objeto de deseo de los países vecinos y hegemónicos.

3. Extensión territorial. La realidad de la superficie extensa y el mito del suelo proveedor de nacionalidad han dinamizado en el imaginario argentino una asociación infundada: la grandeza territorial predice la grandeza política (en la revista, "Argentina tiene casi 3.8 millones de $\mathrm{km}^{2}$. Sus 3800 $\mathrm{km}$ de longitud se extienden desde los $22^{\circ}$ ”). La ITA celebra la vastedad del territorio con especial acento

4. Protagonismo de la naturaleza. La ITA prefiere su difusión a través de atractivos naturales y en virtud de sus características visuales (en el folleto, "La superficie total entre Parques Nacionales, Reservas y Monumentos Naturales es de 4193602 ha”, "grandes ríos”, “imponentes cataratas”, “exuberante hábitat”, “increíble y variada fauna”, "el mayor apostadero de elefantes marinos del mundo", "la mayor concentración continental de pingüinos magallánicos”). La ausencia de mediación de 
códigos culturales en la relación turista-naturaleza supone un mensaje despolitizado: decisión que no deja de ser política. La inclinación por la belleza escénica, la dimensión y la variedad asegura la seducción de colectivos sociales mayores, pero también evita la comunicación de la singularidad argentina: dato necesariamente cultural.

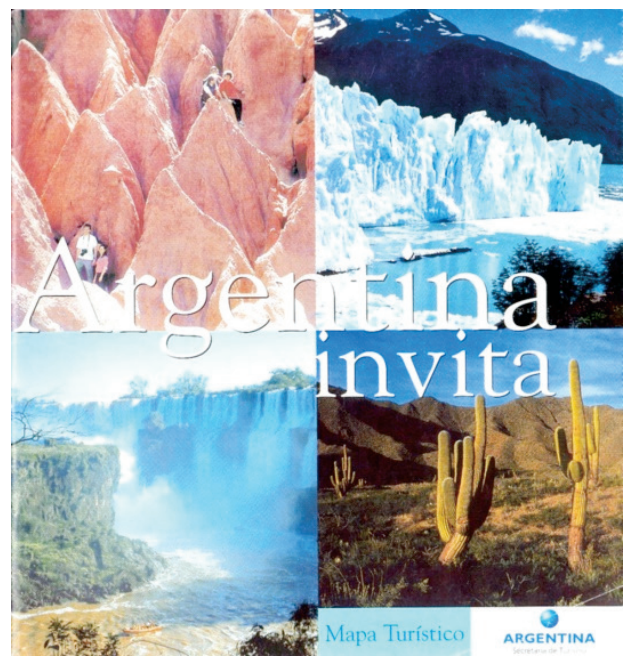

Tapa del mapa turístico

5. Distribución poblacional. La ITA reproduce un territorio deshabitado (o poblado en el pasado) y, por lo tanto, próximo a la idea de barbarie: un planteo que parece sugerir los servicios civilizatorios de las culturas avanzadas. Tal intención es confirmada en la inclusión de presencias foráneas domesticando la naturaleza (en la revista, las pocas presencias humanas consisten en turistas practicando actividades de aventura). En contraste, la masa de la población argentina se agolpa en la capital y concentra cultura y vanguardia, poder y riqueza (en el folleto y el mapa: "La puerta grande... una megalópolis... una de las ciudades más bellas de América Latina... elegancia de fines del siglo xix y la más osada vanguardia”, "casi la mitad [de la población] reside en la Capital Federal y en la Provincia de Buenos Aires; en el mapa: "lo mejor del diseño joven y de vanguardia”; en la revista: “metrópoli global”, "los porteños”, "La 
Avenida Alvear en el elegante barrio de Recoleta"). En este escenario, el Estado no se justifica en una nación (o lo hace con base en la "Nación porteña”) y resulta una institucionalización del territorio y del gobierno.
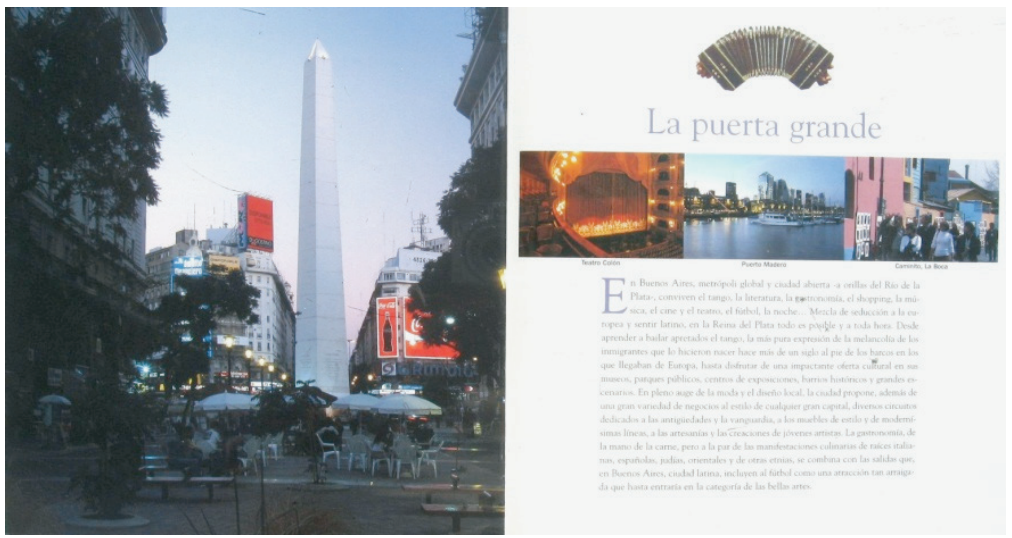

Región Buenos Aires en la revista turística (páginas 2 y 3 )

6. Recorte poblacional. La Secretaría de Turismo difunde una selección sociopolítica nacional organizada alrededor de cinco grupos humanos. Primero, el "grupo de los actores centrales" incluye principalmente a individuos mencionados con nombre propio y ligados con Europa (europeos o descendientes) y por lo común vinculados con el arte de principios del siglo xix (Bustillo, Pelli, Mora, Guido, Fioravanti, Bigatti, Gaudí, Le Corbusier, Rodin, Botero, Thays). A la vez, se excluye a los personajes clásicos de la historiografía nacional y otros protagonistas célebres de la sociedad argentina, como intelectuales, deportistas, religiosos (no son referidos San Martín, Sarmiento, Leloir, Borges, Piazzolla, Gardel).

Segundo, el "grupo destacado" consiste en el conjunto social que el Estado presenta como representativo de la nación: blanco y homogéneo en general, europeos occidentales en particular (en la revista: "Población:... El 95\% es de raza blanca... descendientes de españoles e italianos”).

Tercero, encontramos al "grupo de los arquetipos pintorescos" o colectivo social inclusivo de personajes anónimos y prototipos argentinos, impactantes a los sentidos. La ITA exagera las características de pretéritos indios, gauchos y hombres del tango, a la vez que evita sus (menos 
atractivas) versiones aggiornadas y los introduce desde sus aspectos más pintorescos (en el folleto y el mapa: "la vestimenta de los gauchos").

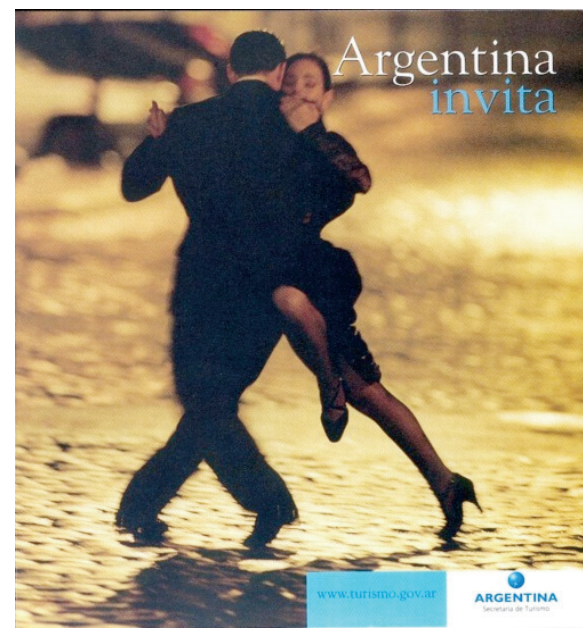

Portada de la revista turística (tapa)

Cuarto, las "comunidades negadas" remiten a la extendida omisión racista de indios (actuales) y a la mención de los negros (históricos y actuales) sólo en perspectiva de su inexistencia (en el mapa, "los ya esfumados habitantes negros”). Excepcionalmente, hay referencia a los aborígenes contemporáneos coincidiendo con el revisionismo identitario que el país experimenta desde los años ochenta.

Los cinco grupos identificados en las publicaciones turísticas responden a un enfoque romanticista del hombre y la sociedad, presente desde los primeros días del Estado argentino y reforzado desde la enseñanza de la Historia, en versión positivista, desde los años cincuenta. La ITA encuentra en esa construcción un material con suficiente pintoresquismo como para integrar sus contenidos, habitualmente estilizados. En síntesis, al lenguaje fotográfico y al recorte natural se suma la cultura fetichizada como núcleo original y distintivo de una imagen turística con pretensiones apolíticas. 
7. Actividades económicas. La ITA comunica una economía caracterizada por las actividades agropecuarias que se desarrollan en la pampa húmeda (en la revista: "un país que sobresale por sus enormes campos"; en el folleto y el mapa: "la llanura pampeana impacta con su horizonte de infinitos cultivos").

En menor medida, también se aprecia cierto desarrollo vitivinícola en Cuyo (por ejemplo, en el folleto y el mapa: "clima ideal para el cultivo de la vid”; en el mapa: "campos plagados de frutales y viñedos”, "tradicionales y modernas bodegas"; en la revista: "los secretos del malbec argentino", "una nutrida carta de cepas", "La Fiesta de la Vendimia en Mendoza”, "Cuyo es el principal productor vitivinícola del país”, "El vino argentino es... uno de los imanes”, "donde se producen la uvas”, "artesanos y enólogos”, "el tradicional torrontés”, "amplia variedad de tintos”).

En un tercer nivel de relevancia, se agrupan otras actividades de diversas regiones: pesca en el Centro, secado de pimientos en el Norte, textiles ovinos y servicios turísticos en la Patagonia y cierto perfil industrial en el Litoral (en la revista: foto de secaderos de pimientos).

8. Instituciones centrales. El gobierno es presentado en la ITA a través de su descripción técnica (en la revista: "Sistema de Gobierno: Republicano, representativo y federal, regido por la Constitución Nacional sancionada en 1853 y reformada en 1994”). Tal caracterización, sostiene un federalismo que es contradicho, por otro lado, en la concepción del territorio en regiones. Asimismo, las publicaciones turísticas incluyen la presentación valorativa del que denominamos Estado romanticista en la repetida referencia a entes del gobierno nacional a cargo de la gestión de la naturaleza y la cultura (Administración de Parques Nacionales; más de una quincena de museos). Consiste en la percepción de la realidad a partir de su faz estética, con eje en la administración de la parte bella del mundo natural y cultural, a la vez que los aspectos conflictivos son silenciados y despolitizados. La ITA además resulta romanticista (en versión doble) al marcar la separación entre domesticación para el interior virgen y alta cultura para la capital urbanizada. 
También, la religión católica (colonial y conversora, jesuítica y colosal) se impone con acento y frecuentemente asociada al Reino de España y a la crisis de la Independencia (en el folleto: "Religión: Católica Apostólica Romana”; en el mapa: "San Ignacio Miní:... La imponencia de sus ruinas revela la magnitud de la acción misionera", "grandes y pequeñas iglesias", "espléndida iglesia del siglo xviI"; en la revista: "cada pueblo celebra el día de su Santo Patrono con procesiones”, "centenares de iglesias y capillas...", "Semana Santa [es] la más relevante de las fiestas").

Fuera del Estado y la religión, la referencia a la Organización de las Naciones Unidas para la Educación, la Ciencia y la Cultura (Unesco) nos habla del respeto argentino por el derecho internacional, pero también de un instrumento de la modernidad occidental para el adoctrinamiento internacional. En efecto, la adhesión argentina a las decisiones del principal organismo educativo, científico y cultural del mundo supone, por una parte, un rasgo de deferencia ante las normas de convivencia internacional. Pero tal organismo también ha sido el medio para la universalización de criterios eurocéntricos (por ejemplo: "Argentina ha sido distinguida por la Unesco”). Por último, el ferrocarril replica la nostalgia por una Argentina y un mundo del pasado (en el mapa: “Tren a las Nubes”).

9. Estructura federal. La organización del espacio turístico en regiones se contradice con la estructura federal del Estado argentino y no recupera la historia, la idiosincrasia ni el valor protagónico de cada unidad provincial en la construcción histórica, constitucional y económica del país como un todo. Por una parte, en la información turística es posible advertir la tradicional preeminencia de la Capital Federal, de la Provincia de Buenos Aires y de la zona pampeana asociada. Por otra parte, las provincias en general y ciertas regiones en particular traslucen omisiones 0 descréditos en su representación. Ambas situaciones son evidentes en el orden en que cada sitio es enumerado, en la descripción desvalorizada del otro geográfico, en las proyecciones nacionales de realidades puntuales, en la omisión o referencia comparativamente superficial, en la mención específica de recursos urbanos sólo para Capital Federal (en la revista: "la calle Florida y la Avenida Santa Fe, los barrios de Belgrano, Palermo viejo y Palermo Hollywood... el Teatro Colón... el Museo Nacional de Bellas 
Artes, el Museo de Arte Latinoamericano de Buenos Aires (MALbA) y el de Arte Hispanoamericano Isaac Fernández Blanco. Los centros culturales Borges, San Martín, Recoleta y Rojas... Feria de San Pedro Telmo... La Bombonera... bares: el ‘Tortoni’... 'La Ideal’ en Suipacha y 'La Biela').

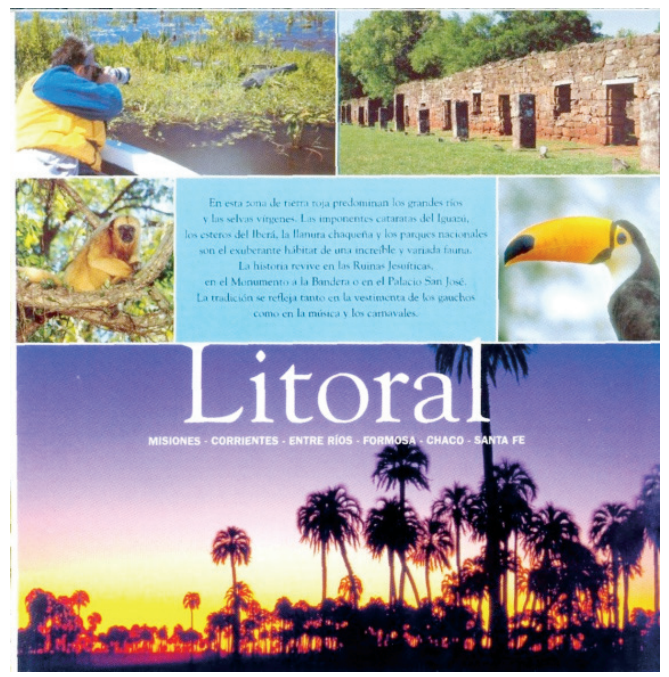

Regiones turísticas en folleto (detalle del reverso)

\section{Discusión}

\section{Contexto internacional pretérito}

La imagen, o representación de la realidad, resulta de una cosmovisión o forma de mirar y concebir el mundo y la historia. En el caso latinoamericano (análogo a otras antiguas colonias europeas), este enfoque reproduce una herencia europea infundida desde la Conquista y reforzada por las inmigraciones (Boldori, 2002: 330 y Mohanty, 2000: 10).

Este locus epistemológico impuesto ha universalizado y encumbrado una historia occidental y su sistema de conocimiento, a la vez que ha disminuido la trascendencia de la perspectiva local, en un proceso de "superación” histórica de las estructuras sociales previas. La historia "universal” se autodenominó 
así por estar centrada en imperios que se expandieron por el globo, aunque se restrinja a Occidente. No se refiere a todo el mundo occidental, sino con preferencia a Europa. Incluso se limita a una porción del occidente europeo: Italia (siglo xv: Renacimiento), Alemania (siglos xvi-xviII: Ilustración y Reforma luterana), Inglaterra (siglo xviI: parlamento), Francia (siglo xviII: Revolución francesa), Holanda, Dinamarca y los países escandinavos; más tarde también se haría extensiva a Estados Unidos. Ese sistema de conocimientos particular, varios siglos más tarde, sigue perteneciendo a los mismos poderes. Efectivamente, hacia la Segunda Guerra Mundial, las ciencias sociales eran patrimonio de unos pocos países occidentales: Francia, Gran Bretaña, Alemania, Italia y Estados Unidos (Dussel, 2002a: 64-65 y 2002b: 45-46; Lander, 2002: 22-23; Mohanty, 2000: 10; Salazar, 1997-1998: 165; Wallerstein, 1999: 23 y 2002: 95 y Zea, 1970: 37).

Asimismo, esta perspectiva recupera una porción temporal particular, enmarcada por los siglos xvi y xix: esto implica que antes del Renacimiento abundaba la oscuridad; en el siglo xviI, en cambio, ya se había consolidado la expansión de Occidente por el mundo. Extendida por todo el orbe y apropiada de todas las culturas, Europa se encontró con la posibilidad de reorganizar la descripción y explicación del tiempo y el espacio en una "gran narrativa universal" con centro espacial y temporal en Europa (eurocentrismo o etnocentrismo europeo e ilustrado). Los planisferios y mapamundis son solo un ejemplo de la operación (Dussel, 2002a: 65 y 2002b: 48; Jacovella, 1981: 46; Lander, 2002: 16 y 23 y Wallerstein, 2002: 95).

Tal "narrativa" decidió una "historia como línea ascendente" (Zea, 1970: 42): relato evolutivo de la idea de progreso que facilitó la jerarquización de los pueblos. Para consolidar la idea, se desarrolló una filosofía de la historia o pensamiento que rastreaba en el pasado los fundamentos del progreso alcanzado y en necesario crecimiento. En este marco, la sociedad liberal pasó a ser el modelo a seguir y las sociedades que no lograran sumarse a esta dinámica estarían confinadas a desaparecer: un desenlace preanunciado para nuestros pueblos en virtud de insuficiencia en términos de raza, cultura, vida política y económica (Lander, 2002: 22-25 y Wallerstein, 2002: 105).

Esta epistemología occidental no pudo describir y explicar los fenómenos latinoamericanos (o no occidentales) desde las causalidades vertebrales locales y desde la especificidad de sus sujetos. Entonces fueron considerados primitivos 
e inferiores. En consecuencia, y de la mano de la dominación fáctica, las expresiones culturales nativas resultaron eliminadas, reprimidas, silenciadas o adaptadas ("civilizadas") a los modelos autorreferenciados europeos. Es así como las construcciones sociales latinoamericanas no pasaron a formar parte del corpus "universal" o, al menos, no como tales. Concretamente, quedaron fuera de la historia numerosos acontecimientos y sujetos amenazantes (anarquistas, socialistas y otros), procesos de automodernización y conocimientos científicos nativos: todos amontonados en la idea de la alteridad. Como resultado, la discriminación u ocultamiento de los diversos sujetos latinoamericanos supone una doble exclusión: la geográfica por un lado y la particular de género, raza, religión o política, por otro; se constituye así un modelo de comprensión e interpretación de la realidad incompatible con la idea de equidad y particularidad (Boldori, 2002: 156; Jacovella, 1981: 18; Lander, 2002: 16 y 24; Mohanty, 2000: 10-11 y 24 y Salazar, 1997-1998: 167).

Claro que este legado se combinó localmente con una actitud particular al momento de asimilar la experiencia: los sentimientos de inferioridad y de vergüenza por la propia cultura fueron una constante en todas las antiguas colonias europeas. Los criollos (americanos hijos de colonizadores) sintieron que vivían desterrados de la historia en una cultura ajena y precaria: un confinamiento impuesto y decidido por sus ancestros ambiciosos de riquezas. Así, el hombre latinoamericano, afirmado en su herencia europea, reclamaba el derecho al patrimonio occidental moderno. Ese sentimiento se reavivó, en el caso argentino, con las posteriores y masivas inmigraciones europeas. Este es el origen de la histórica imitación de la cultura europea moderna por parte de la latinoamericana: copia de constituciones, normativa, formas de organización, pensamiento filosófico, estilos artísticos, sistema económico. Inútilmente, se pensó que imitando el producto final se adquiriría la esencia. Pero, ante el insuficiente resultado, constantemente sobrevino la decepción (Boldori, 2002: 330; Mohanty, 2000: 10 y Zea, 1970: 14-24). En suma, como señala Leopoldo Zea, "la historia de la cultura iberoamericana es una historia en la que sus hombres realizan una permanente quema de naves, una renuncia permanente a lo que son, para el logro de lo que no solo no son, sino que se evita lleguen a ser. Una historia en la que se alterna la admiración por los grandes pueblos que le sirven de modelo con la amarga queja de la actitud de estos pueblos frente a sus admiradores" (1970: 36). 
En un ajustado resumen histórico, es posible caracterizar el proceso con un comienzo en la Conquista. Los procesos libertarios no cambiaron mucho las cosas: las antiguas colonias ahora independientes siguieron mirándose con lentes europeas. Así, en la primera parte del siglo xx, las masas empezaron a rebelarse contra la exclusión propia de la industrialización y la corrupción del gobierno, "hacia 1910, se había hecho palmario que Occidente, allí, era inferior a Occidente” (Salazar, 1997-1998: 168). Las élites locales, entonces, reeditaron instrumentos de las antiguas élites extranjeras y ajustaron los enfoques teóricos sociales. Entre las décadas de los cincuenta y setenta, la crisis del modelo desarrollista condujo al cuestionamiento de la visión impuesta y Occidente respondió con "marxismo vulgar" y golpismo antipopulista o anticomunista, según correspondiera. En consecuencia, la producción de conocimiento se tiñó de praxis política y los sujetos marginados no modificaron su rol. De este modo, producto destacado de la modernidad, el neoliberalismo como último formato de la cultura occidental se extiende cómodamente desde los años ochenta hasta nuestros días (Mohanty, 2000: 11 y Salazar, 1997-1998: 168-171).

A lo largo de ese devenir histórico, Occidente logró imponer en el mundo un sistema epistemológico funcional a su hegemonía. En este contexto, el paradigma de las ciencias sociales modernas, nacidas en respuesta a problemas europeos, evidencia su sesgo en varios aspectos institucionalizados en el mundo académico-científico que, finalmente, caracterizan una episteme más provinciana y dependiente que universal y autocentrada (Jacovella, 1981: 1621 y 45-46; Lander, 2002: 16-23 y 30; Mohanty, 2000: 10; Salazar, 1997-1998: 165-170; Van Langenhove, 1996: 3; Wallerstein, 1999: 4 у 20-23 у 2002: 96-106), caracterizada por:

1. Forzada universalidad. La filosofía fue reemplazada por la ciencia cartesiano-newtoniana como forma de conocimiento preferida; se buscó descubrir los patrones constantes del comportamiento humano y social, convencidos de la posibilidad de proyectarlos en el tiempo y el espacio. El modelo europeo, en este contexto, fue presentado como mecánicamente extrapolable al resto del mundo y como su espejo futuro.

2. Vigencia del ethos occidental. Un conjunto de valores eurocéntricos fueron infundidos a las posesiones ultramarinas, ahí se naturalizaron como referentes únicos y trascendieron los días coloniales: civilización y 
modernización, ilustración e iluminismo, elitismo y autoritarismo, secularismo y moral universal, capitalismo y mercantilismo, liberalismo y neoliberalismo, consumismo y materialismo, industrialización y urbanización, ciencia y tecnología positivista y fragmentada, ley y arte autónomos, estética romanticista y pintoresquista, fetichista y costumbrista. La dominación fáctica y la epistemológica se reforzaron mutuamente, con el auxilio de diversas herramientas: un derecho "universal" que dicta un determinado "deber ser”; una convicción de superioridad explicada desde méritos inherentemente europeos; un Estado producto de filosofías ajenas antes que de la propia realidad social.

3. Posicionamiento de las ideas de "progreso" y "desarrollo", en el sentido de crecimiento económico con un punto de llegada fijado por el modelo occidental. Después de la Segunda Guerra Mundial se reemplazó la desacreditada categoría manchada de "civilización” por nuevos sustitutos políticamente correctos. Entonces, la ciencia social asumió el rol positivista de calcular la desviación respecto del crecimiento occidental: luego el rótulo de "subdesarrollado", en reemplazo de "premoderno" o "bárbaro", fue científicamente confirmado a través de mediciones. Asimismo, el ideal desarrollista llevó a que la acción política demandara una ciencia social "aplicada", funcional a sus nuevas necesidades de “ingeniería social”.

4. Fragmentación de la historia en periodos. Producto de una interpretación Whig de la historia, se practicó un escalonamiento determinista y evolucionista del tiempo que supuso un presente como resultado necesario y mejorado del pasado (prehistoria, Colonia, República). La comprensión del "tiempo espacio" como categorías físicas antes que antrópicas facilitó su naturalización.

5. Separación del conocimiento social. Con el predominio sobre las culturas del mundo fue posible reorganizar el tiempo y los saberes. Por una parte, se practicaron divisiones entre el pasado (historia) y el presente, y entre lo propio (estudios clásicos) y lo ajeno (antropología y orientalismo). Por otra parte, la ideología liberal fragmentó el presente en temas públicos 0 del Estado (ciencia política), temas privados o del mercado (economía) y 
temas colectivos o de la sociedad (sociología). El divorcio entre ciencia, filosofía y humanidades es característico de esta episteme, así como la "separación de la búsqueda de lo verdadero y la búsqueda de lo bueno y lo bello” (Wallerstein, 2002: 114).

6. Confirmación científica de la inferioridad del "otro" no occidental. Los pueblos sometidos representaron para Europa la posibilidad de tener una alteridad inferior; luego, esos sujetos no occidentales fueron concebidos con prejuicio a partir de un constructo exagerado y uniforme. Este es el origen de la antropología, dedicada inicialmente al estudio de los pueblos ágrafos, así como del orientalismo, a cargo de la descripción de las culturas letradas que no forman parte del núcleo central de la "historia universal” eurocéntrica.

7. Consagración de metodologías positivistas. La historia basada exclusivamente en consultas a registros ("empirismo archivístico") se perpetuó más allá de la Colonia; así, la revisión de colecciones reales (Archivo General de Indias, Archivo de la Capitanía General, actas capitulares) fue relevada por el examen de otros documentos durante la República (ordenanzas, leyes, resoluciones, decretos, epistolarios y memorias de "prohombres").

8. Selección de problemas e indicadores, temas y categorías. La imposición de criterios para el tratamiento científico es evidente en la historia; en efecto, la versión europea, plena de "gestas de conquistadores y civilizadores", originó una historia latinoamericana de "gestas políticas de caudillos y estadistas (civilizadores), de militares (disciplinadores), o de empresarios (modernizadores)” (Salazar, 1997-1998: 166).

9. Creación de estructuras específicas para la institucionalización del saber moderno. Después de la Revolución francesa, en Europa se habilitaron nuevas universidades, se abrieron cátedras que siguieron las "disciplinas” comentadas y se fundaron asociaciones científicas para asegurar el sistema.

Todo este bagaje epistemológico occidental configuró una dialéctica de poder-conocimiento, tanto en el plano global como en el regional. En este sentido, 
Mohanty (2000: 10 y 24), desde la India, indica que la dominación europea sobre sus colonias desplegó recursos militares complementados con un "sistema de conocimientos": modelo autoritario de modernización que fue retomado por las clases dirigentes del Tercer Mundo para consolidar su poder.

También Wallerstein (1999: 4 y 2002: 101 y 105) recuerda que la colonización francesa asumió un sentido misional y civilizatorio; reeditado más tarde por el rescate desarrollista de los intelectuales europeos de la posguerra sobre el Tercer Mundo o periferia de la "economía-mundo capitalista" y nuevamente presente en el "derecho a intervenir" en diferentes conflictos políticos mundiales durante la década pasada. El mismo autor observa que el orientalismo, o constructo occidental sobre las características de los pueblos no occidentales, constituyó una categoría funcional a la dominación colonial. Se trata de una dinámica en la misma línea de la idea de dominación simbólica de Weber para la legitimación de los sistemas hegemónicos y conducente a la figura del Estado seductor de Debray: "una lógica de dominación depende siempre de una logística de los símbolos" (1995: 60-61).

Este esquema de interpretación es referido con palabras diferentes por varios autores respecto de Latinoamérica. Así, Salazar (1997-1998: 167) señala que el "discurso universalizador" ("aristocrático, mitificado, conservador y rigidizado") propio de la cultura occidental tuvo la función de perpetuar a las oligarquías en el poder. Boldori (2002: 156), por su parte, encuentra en la literatura mercosureña intentos de conquista del poder mediante el "control de la producción simbólicodiscursiva”. En la misma línea, Lander (2002: 16 y 23) desnuda la “dialéctica conocimiento-dominación” al entender la conquista como el comienzo de un proceso de "organización colonial del mundo" y "constitución colonial de los saberes, de los lenguajes, de la memoria” por parte de Occidente: luego, el "lugar de enunciación" está ligado con el poder como dominación. También considera al neoliberalismo como un "discurso hegemónico de un modelo civilizatorio", y a la "construcción eurocéntrica" como un "dispositivo de conocimiento colonial e imperial". Coincidentemente, otros autores entienden que a través de la dinámica de dominación-dependencia global, las potencias europeas impusieron una "estructura de conocimiento" como reaseguro del poder desde la epistemología. 
La justificación de la dominación fáctico-epistemológica suele tocar clarines misionales respecto del ethos occidental. En efecto, Zea (1970: 28-29 y 31) entiende que Occidente tiene por misión incorporar a Latinoamérica, inmadura desde el prisma de la modernidad, a la historia "universal": luego, la expansión de su historia es parte del proceso de colonización política. En un sentido análogo, Lander (2002: 24) advierte que Occidente, convencido de su estatus superior, solo encuentra dos opciones para las culturas diferentes e inferiores: “Aniquilación o civilización impuesta”. También Dussel (2002a: 58-68 y 2002b: 48-53) plantea el "mito de la Modernidad” en términos similares: la civilización moderna, consciente de su superioridad, se siente obligada y con derecho a modernizar al resto del mundo atrasado ("falacia del desarrollismo") y, ante la resistencia bárbara, tiene justificado el recurso a la violencia: así, las víctimas son los culpables y los sacrificios son necesarios y liberadores. La misma excusa "civilizatoria" es compartida por Wallerstein, quien observa la expansión de la ciencia moderna por el mundo como una forma de comprender las dinámicas culturales extraeuropeas y facilitar su civilización: "Las ciencias sociales se convirtieron [...] en un instrumento para gobernar de manera inteligente” (1999: 23). En el mismo sentido, Dallanegra Pedraza (1997: 3) denuncia la "política de penetración cultural" de las potencias centrales como una herramienta esencial del "proceso de dominación estructural" sobre los países "sur", en el marco de la "relación dominación-dependencia” que se complementa con la sujeción económica y las acciones de segmentación: solo eventualmente las élites de los países desfavorecidos adoptan una cosmovisión con teorías y doctrinas exógenas.

Se puede sintetizar la idea en la consideración de un sistema hegemónico que pretende monopolizar el espacio y perpetuarse en el tiempo. La primera intencionalidad justifica su expansión político-económica, y la segunda el ajuste epistemológico-simbólico: ambos procesos se refuerzan entre sí. La manipulación de los símbolos y los saberes, por cierto, comienza en el discurso, toma la historia y se instala en la episteme. Se trata de una dominación a la vez violenta y persuasiva.

Hechas estas reflexiones se puede advertir que, en el marco del proceso de modernización, la ITA adquiere una explicación más precisa a su característica eurocéntrica. En efecto, se trata de contenidos que resumen un saber turístico 
con origen en un Occidente moderno, que se nutre a la vez de otros frutos de la perspectiva eurocentrada: los saberes histórico-geográficos (Navarro, 2012). En este contexto encuentra fundamento el geoposicionamiento próximo a Europa y distante de Latinoamérica, la autopercepción como alteridad inculta (inhóspita y pastoril) que reclama servicios civilizatorios, la omisión de comunidades locales "premodernas" y de personajes libertarios o librepensadores, el recorte poblacional racista, la fragmentación del territorio nacional en regiones sin fundamento de comunidades preexistentes y el peso del criterio estético-cultural de la Unesco.

Se observa asimismo que la ITA prefiere fotos y textos descriptivos y vistosos; recursos y atractivos turísticos naturales o culturales fetichizados y grandes, decimonónicos y bellos (según un ideal de belleza impuesto); representaciones pintorescas y costumbristas de la población; la presentación del Estado en su vertiente de administrador de la naturaleza y la alta cultura; además de gestos nostálgicos. En suma, una concepción romanticista y moderna de la realidad; en particular, la propia realidad como un otro bárbaro que no posee valores relevantes para transmitir. De este modo, resulta una ITA doblemente moderna: por el sesgo de los saberes de los que se nutre (factor cualitativo) y por el impacto sensorial que está condenada a ejercer (factor cuantitativo).

\section{Contexto internacional contemporáneo}

En el contexto del proceso de modernización operado en los últimos 500 años es posible ver la etapa más reciente, llamada globalización, que supone un nuevo formato de dominación y/o hegemonía político-cultural sustentada en la sofisticación tecnológica. La teoría de sistemas mundiales entiende la globalización como la difusión a escala global de la modernidad y el capitalismo (Held y McGrew, 1999: 12). En la misma línea, Noam Chomsky asimila la globalización con "programas socioeconómicos neoliberales [de] ideólogos occidentales" (2004: 39). También Mlinar, desde las teorías pluralistas, observa una globalización en términos de afirmación del sistema global sobre los sistemas inferiores: una serie de incrementos de las relaciones asimétricas que determinan vínculos de dominación y dependencia, imitación de los sistemas locales respecto de los globales y homogeneización del sistema total (Attinà, 2001: 74). Wolton (2004), 
por su parte, ve en la "mundialización de las informaciones" una forma de "imperialismo cultural" impuesto desde el "norte" y de molde occidental.

Con este marco, en el contexto de un sistema mundial que pertenece a una misma cosmovisión y que incluye relaciones asimétricas de poder, se entiende que, por un lado, la globalización afianza la distribución y homogeneización de valores y conocimientos, problemas e indicadores occidentales; y, por otro, refuerza la jerarquización internacional entre Estados, élites y sujetos poderosos y sus contrapartes dependientes. Con el auxilio de las tecnologías de información y comunicación (TIC), los entes que concentran el poder disponen de una infraestructura global interconectada que, además, agiliza la institucionalización global de prácticas relacionales (comercio, turismo, democracia). Este andamiaje para la transmisión y recepción en la arena mundial acelera la globalización cultural, fenómeno que va de la mano de la estratificación y las desigualdades (Held y McGrew, 1999: 19 y 330-331).

Poder y cultura siguen uno pegado al otro. Las identidades culturales de los países dominados fueron en gran parte arrasadas junto con sus sujetos y reemplazadas por parte de la ideología modernista. La dinamización del transporte y las comunicaciones que representa la globalización tienden a acelerar aquel proceso modernizador y a eliminar las identidades nativas o mestizas. La porción de cultura que se mundializa o exporta es la perteneciente a las élites del mundo occidental, sujetos cuya identidad no está en riesgo porque poseen los medios para resguardarla. Este fenómeno es referido por Wolton como la falacia de la "cultura mundial", del "ciudadano del mundo" o "cosmopolitismo de aeropuerto" (2004), en ajustada referencia a aquellos que participan del turismo internacional: solo $3.5 \%$ de la población mundial. Esto significa que los pocos que viajan viajarán más: crecerá la cantidad de viajes de los mismos pocos viajeros. En este sentido, se observa una tendencia hacia la hegemonía de la modernidad, antes que una "posmodernidad": no se trata de una etapa nueva (mucho menos diferente o antagónica), sino del afianzamiento de la misma. En suma, la ITA analizada, doblemente moderna, tiene entonces un doble reto: el desafío de combinar verdad y belleza. 


\section{Conclusión}

Dispuestos a comprender la ITA, el presente análisis trasciende el espacio y el tiempo del Estado argentino para dar con "regularidades" explicativas y "fuerzas profundas”, en línea con Duroselle (1998: 41 y 340-342): manifestaciones extendidas en el mundo y en un periodo histórico extenso, que deciden el paradigma en el que se inscribe nuestro objeto de estudio.

Se advierte entonces que en el último medio milenio, desde el Occidente desarrollado, se ha ejecutado una estrategia de dominación político-fáctica del mundo que operó de la mano de la dominación cultural-epistemológica. Este proceso, denominado modernización, supone una decisión hegemónica que ha reprimido, modelado, domesticado o eliminado las formas locales de autonomía y conocimiento en pos del objetivo de perpetuación en el poder de sus ejecutores. La ITA se inscribe en tal episteme y así lo denotan las características de sus contenidos aquí analizados.

En la actualidad se asiste, además, a un proceso de globalización que es una continuación efectiva del proceso modernizador o estructura de dominación fáctico-epistemológica de Occidente, solo que acelerado y profundizado por los avances tecnológicos. En este contexto, la edición de una ITA que reproduzca la identidad y el territorio argentinos despojados de enfoques eurocentrados redobla el desafío que supone construir un mensaje propio, autónomo y, a la vez, efectivo y convincente.

\section{Fuentes CONSULTAdAs}

Attinà, Fulvio (2001). El sistema político global. Introducción a las relaciones internacionales. Buenos Aires: Paidós.

Boldori, Rosa (2002). La identidad cultural del Mercosur. Buenos Aires: Ciudad Argentina.

Chomsky, Noam (2004). Hegemonía o supervivencia. Buenos Aires: Norma. Dallanegra Pedraza, Luis (1997). Evolución del debate teórico-epistemológico sobre las relaciones internacionales. Buenos Aires: edición del autor.

Debray, Régis (1995). El Estado seductor. Las revoluciones mediológicas del poder. Buenos Aires: Manantial.

104 Duroselle, Jean-Baptiste (1998). Todo imperio perecerá. Teoría sobre las relaciones internacionales. México: Fondo de Cultura Económica. 
Dussel, Enrique (2002a). "Eurocentrismo y modernidad (Introducción a las lecturas de Frankfurt)”, en Walter Mignolo (comp.). Capitalismo y geopolítica. El eurocentrismo y la filosofía de la liberación en el debate intelectual contemporáneo. Buenos Aires: Ediciones del Signo, 57-70.

------- (2002b). “Europa, modernidad y eurocentrismo”, en Edgardo Lander (comp.). La colonialidad del saber: eurocentrismo y ciencias sociales. Perspectivas latinoamericanas. Buenos Aires: Consejo Latinoamericano de Ciencias Sociales (Clacso), 41-53.

Held, David y Anthony McGrew (1999). Global Transformations. Politics, Economics and Culture. Cambridge: Polity Press.

Jacovella, Guillermo (1981). La Argentina: su lugar en el mundo. Bases culturales de nuestra política exterior en América Latina. Buenos Aires: Pleamar.

Lander, Edgardo (2002). “Ciencias sociales: saberes coloniales y eurocéntricos”, en Edgardo Lander (comp.). La colonialidad del saber: eurocentrismo y ciencias sociales. Perspectivas latinoamericanas. Buenos Aires: Clacso. Mohanty, Manoranjan (2000). Contemporary Indian Theory. Nueva Delhi: Sanskriti.

Navarro, Diego (2008). "La imagen turística argentina: aspectos políticos”. Afuera. Estudios de crítica cultural [en línea], III (5), noviembre. Disponible en http://www.revistaafuera.com/NumAnteriores/ pagina.php? seccion $=$ Articulos $\&$ page $=05$. Articulos . Navarro. htm\&idautor $=115$ [2012, 1 de junio].

------- (2010). Imagen turística argentina. Política turística y política exterior. Mendoza: Universidad del Aconcagua.

(2012). "Rasgos de la identidad política argentina en la promoción turística nacional”. Afuera. Estudios de crítica cultural [en línea], VII (11), mayo. Disponible en http://www.revistaafuera.com/articulo. php?id $=205 \&$ nro $=11$ [2012, 1 de junio $].$

Otero, Hernán (1997). "Investigando a investigadores del pasado”, en Catalina Wainerman y Ruth Sautu. La trastienda de la investigación. Buenos Aires: Lumiere.

Salazar, Gabriel (1997-1998). Historia. Boletín de Filosofía, 9 (1), Universidad Católica Blas Cañas, Santiago de Chile. 
Sautu, Ruth (1997). "Acerca de qué es y no es investigación científica en ciencias sociales", en Catalina Wainerman y Ruth Sautu. La trastienda de la investigación. Buenos Aires: Lumiere.

Van Langenhove, Luk (1996). Reflexiones para un replanteamiento de las ciencias sociales [en línea]. Organización de las Naciones Unidas para la Educación, la Ciencia y la Cultura. Disponible en http://www. unesco.org/most/igc99rs3.htm [2012, 1 de junio].

Wallerstein, Immanuel (1999). Impensar las ciencias sociales. Limites de los paradigmas decimonónicos. México: Siglo xxI Editores.

------- (2002). "El eurocentrismo y sus avatares: los dilemas de las ciencias sociales", en Walter Mignolo (comp.). Capitalismo y geopolítica. El eurocentrismo y la filosofía de la liberación en el debate intelectual contemporáneo. Buenos Aires: Ediciones del Signo, 95-116.

Wolton, Dominique (2004). La otra munidalización. Los desafíos de la cohabitación cultural global. Barcelona: Gedisa.

Zea, Leopoldo (1970). América en la historia. Madrid: Ediciones de la Revista de Occidente. 